\title{
EVALUASI PENGELOLAAN EKOSISTEM MANGROVE PADA DAERAH PERLINDUNGAN LAUT DI DESA BLONGKO, KECAMATAN SINONSAYANG KABUPATEN MINAHASA SELATAN PROVINSI SULAWESI UTARA
}

\author{
Joshian N.W. Schaduw \\ Dosen Fakultas Perikanan dan IImu Kelautan,Universitas Sam Ratulangi, Manado \\ E-mail: nicolas_schaduw@yahoo.com
}

\begin{abstract}
Mangrove ecosystem in Blongko village has many functions for coastal area. The aims of this research was to describe potential and the existing condition of mangrove ecosystem and also to give directive policy strategic for conservation mangrove ecosystem in this area. This research used primary and secondary data. Primary data was gathered by field observation and in-depth interview with 100 respondens by questionnary. Secondary data was gathered by unravel various literature and related institution. The development indicators was used to determine the policy strategic of sustainable mangrove ecosystem. Its was threat, factor, and constraint causing degradation mangrove ecosystem. This research got three policy strategy to carry on of sustainable mangrove ecosystem. Its was increase of human resources quality, protection and continuation of mangrove ecosystem, and low and institution reinforcement. This strategy was expected to depress degradation in mangrove ecosystem.
\end{abstract}

Keywords : Coastal Area; Blongko village; Mangrove Ecosystem; Policy Strategy.

\section{PENDAHULUAN}

Desa Blongko merupakan desa percontohan bagi program perlindungan pesisir dan laut berbasis masyarakat. Desa ini memiliki daerah perlindungan laut (DPL) yang luasnya sekitar $12 \mathrm{Ha}$, sedangkan luas keseluruhan dari ekosistem mangrove di Desa Blongko sekitar $15 \mathrm{Ha}$. Tujuan pengadaan daerah perlindungan laut adalah meningkatkan produksi perikanan di sekitar daerah perlindungan laut sekaligus melindungi keanekaragaman makhluk hidup dan terumbu karang di dalam daerah perlindungan laut. Upaya ini dalam jangka panjang dapat meningkatkan kualitas hidup masyarakat yang menjaga dan mengelola daerah perlindungan laut tersebut.

Ekosistem mangrove pada desa ini kembali terpelihara dengan baik ketika ada program pembuatan daerah perlindungan laut yang melibatkan pemerintah dan masyarakat. Akan tetapi setelah tahun 2005 dengan berakhirnya Proyek Pesisir di daerah ini, terlihat adanya indikasi kerusakan ekosistem mangrove. Hal ini dikarenakan masyarakat kembali melakukan kegiatan yang bersifat destruktif seperti menebang pohon mangrove untuk keperluan sehari-hari, ketidaksabaran dan ketidakpuasan sebagian masyarakat dalam menunggu manfaat dari DPL dan perbedaan pemahaman masyarakat tentang DPL.

Melihat akan permasalahan yang terjadi pada DPL Blongko setelah kurang diperhatikan oleh pemerintah, maka perlu dilakukan suatu penelitian untuk mengetahui potensi sumberdaya ekosistem mangrove di Desa Blongko dan keterlibatan masyarakat dalam pengelelolaan ekosistem mangrove sesuai dengan dengan karakteristik masyarakat, agar dapat menghasilkan suatu strategi yang baik dalam pengelolaan sumberdaya ekosistem mangrove.

Penelitian ini mempunyai tujuan untuk mendeskripsikan kondisi dan potensi ekosistem mangrove Desa 
Blongko serta mengidentifikasi faktorfaktor yang memengaruhi kondisi dan potensi tersebut. Selain itu identifikasi juga dilakukan terhadap faktor-faktor yang memengaruhi partisipasi masyarakat dan peran pemerintah dalam upaya pelestarian ekosistem mangrove. Identifikasi terhadap hal-hal yang telah disebutkan tadi bertujuan untuk menciptakan suatu strategi pelestarian ekosistem mangrove berbasiskan masyarakat yang berkelanjutan di Desa Blongko.

Manfaat yang diharapkan dari penelitian ini adalah memberikan informasi tentang kondisi ekosistem mangrove Desa Blongko serta partisipasi masyarakat dalam upaya pelestarian ekosistem mangrove. Hal ini akan menjadi masukan kepada pemerintah selaku pembuat kebijakaan dan pengambil keputusan, baik dalam perencanaan, pemanfaatan, dan pelestarian sumberdaya alam yang berkelanjutan, khususnya terhadap sumberdaya yang ada pada ekosistem mangrove di Desa Blongko.

\section{METODOLOGI PENELITIAN}

Penelitian ini dilakukan pada ekosistem mangrove yang terdapat di Desa Blongko, Kecamatan Sinonsayang, Kabupaten Minahasa Selatan, Provinsi Sulawesi Utara. Letak posisi geografis Desa Blongko adalah 124020'45"124021'15" BT dan 01007'35"-01009'00" LU.

Penelitian ini dilaksanakan dalam tiga tahap. Tahap awal yang ditempuh adalah survey pendahuluan. Pada tahap ini kegiatan yang dilakukan adalah pengumpulan data sekunder lokasi penelitian dari studi pustaka mengenai Desa Blongko dari beberapa pustaka yang ada. Tahap ini dilakukan untuk mendapatkan informasi dari Desa Blongko, berupa profil desa dan data kawasan mangrove yang ada. Tahap selanjutnya adalah pengambilan data primer di lokasi penelitian. Data primer yang dikumpulkan adalah data vegetasi mangrove beserta kondisi biofisik dan kondisi sosial ekonomi masyarakat. Tahap yang terakhir adalah tahap pengolahan data dan penulisan hasil penelitian.

Data yang dikumpulkan dalam penelitian ini meliputi data vegetasi mangrove, data hasil tangkapan, data fauna pada ekosistem mangrove, data morfologi pantai, data fisik ekosistem mangrove, dan data keadaan sosial ekonomi. Data primer diambil langsung pada saat penelitian melalui sampling, observasi, kuisioner, dan wawancara terbuka/langsung dan secara mendalam di lokasi penelitian. Data sekunder didapatkan dari beberapa instansi terkait seperti Fakultas Perikanan dan IImu Kelautan Universitas Sam Ratulangi, Departemen Kehutanan, Departemen Kelautan dan Perikanan, BAPPEDA, Birdlife, pemerintah daerah baik tingkat desa sampai tingkat provinsi, dan sumbersumber lain yang mempunyai data berkaitan dengan kebutuhan penelitian ini.

Data sosial ekonomi dikumpulkan secara langsung dengan cara wawancara yang berpedoman pada kuisioner. Sedangkan data jumlah penduduk, mata pencaharian, dan tingkat pendidikan diperoleh dari kantor desa dan kantor kecamatan setempat.

Responden dipilih sebagai unit penelitian dengan metode penarikan contoh acak secara sengaja. Responden yang dipilih adalah masyarakat yang sering berasosiasi dengan mangrove yang tinggal di pesisir Desa Blongko. Responden yang diwawancarai berjumlah 100 orang yang terdiri atas aparat desa dan kecamatan, pengelola DPL, dan masyarakat desa yang sering beraktivitas pada ekosistem mangrove. Responden yang dipilih adalah responden berusia dewasa atau yang berusia 17 tahun keatas. 


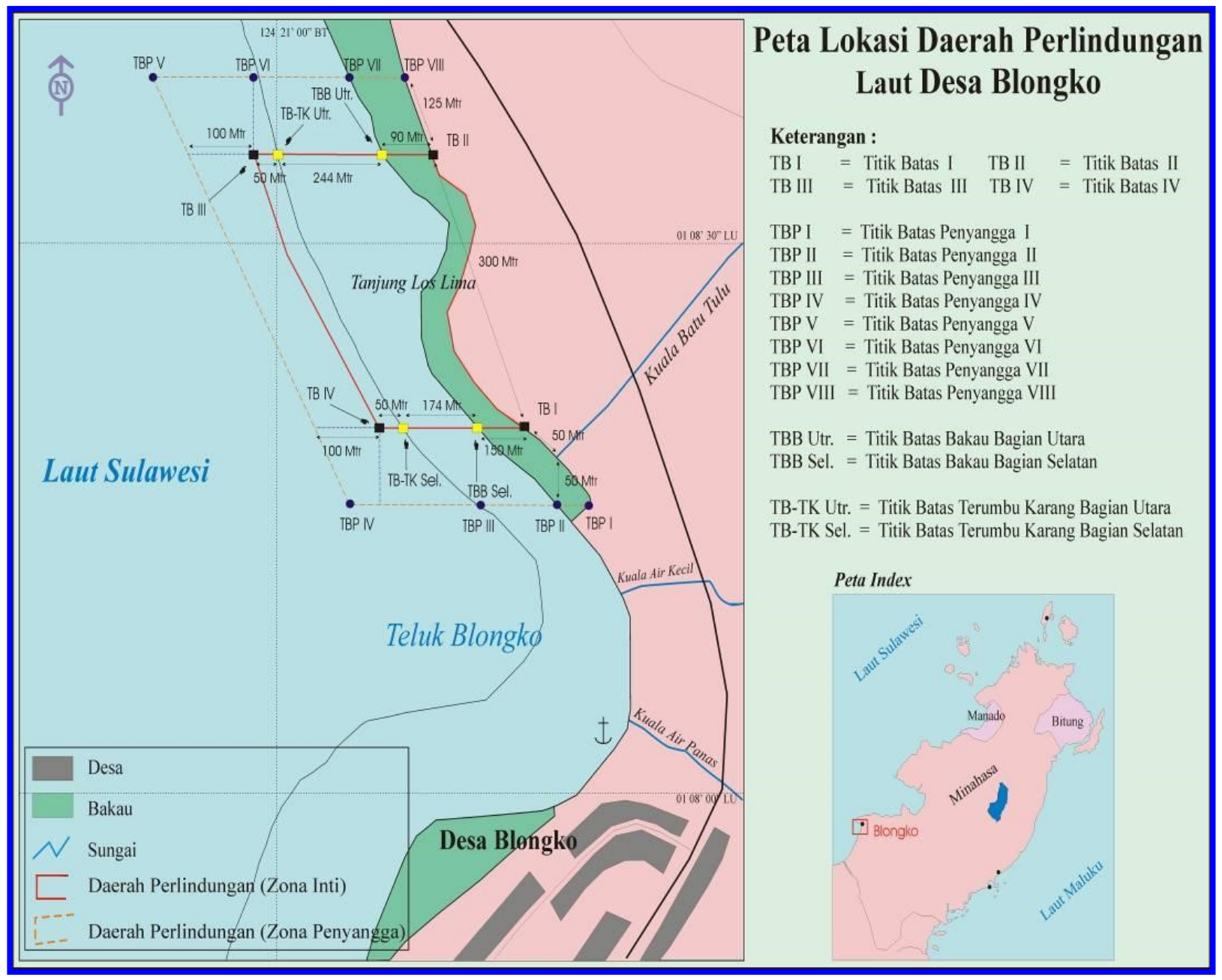

Gambar 1. Peta Lokasi Penelitian DPL Desa Blongko

Penilaian terhadap indikator pembangunan berkelanjutan ekosistem mangrove dilakukan dengan melihat data yang telah diperoleh sebelumnya dan dianalisis menggunakan nilai sederhana yang ditabulasi untuk mempermudah interpretasi terhadap dimensi yang dinilai. Jumlah bobot pada masing-masing dimensi adalah 10. Bobot yang diberikan terhadap beberapa indikator berbeda, hal ini disesuaikan dengan prioritas suatu permasalahan dalam dimensi tersebut. Indikator yang memiliki prioritas yang lebih penting mendapatkan nilai yang tinggi dibandingkan yang lain.

Nilai pada masing-masing indikator berupa nilai mutu ( $A, B$, atau $C$ ). Hasil perkalian antara bobot dari indikator dan nilai yang diberikan terhadap indikator merupakan skor dari masing-masing indikator. Jumlah dari skor pada masingmasing dimensi menjadi acuan dalam menentukan prioritas alternatif strategi pelestarian ekosistem mangrove. Peringkat alternatif strategi ditentukan dengan melihat jumlah skor dari masingmasing dimensi. Dimensi yang memiliki nilai terkecil mendapatkan prioritas utama diikuti dengan dimensi yang lain. 
HASIL DAN PEMBAHASAN

Ketidakberhasilan DPL yang ada di Sulawesi Utara disebabkan oleh rendahnya pemahaman masyarakat tentang arti pentingnya pelestarian ekosistem pesisir bagi lingkungan dan manusia. Dalam Wantasen (2002) dan Manembu (2004) dapat dilihat bahwa kendala yang dihadapi DPL Desa Talise, Pulau Gangga, dan Pulau Bangka adalah rendahnya pemahaman masyarakat akan pentingnya pelestarian ekosistem pesisir serta rendahnya tingkat partisipasi berbasis masyarakat.

Tabel 1. Partisipasi Masyarakat dan Tingkat Pemahaman Terhadap Ekosistem Mangrove

\begin{tabular}{ccccc}
\hline Kriteria & Tingkat & \multicolumn{2}{c}{ Jumlah Responden } & \multirow{2}{*}{ Kategori } \\
\cline { 3 - 4 } Penilaian & Partisipasi & Jiwa & $\%$ & \\
\hline Sosialisasi, Perencanaan & Tinggi & 12 & 18,00 & Rendah \\
dan pelatihan & Sedang & 53 & 47,00 & \\
& Rendah & 35 & 35,00 & \\
\hline Pelaksanaan Program & Tinggi & 15 & 15,00 & Rendah \\
& Sedang & 51 & 51,00 & \\
& Rendah & 34 & 34,00 & \\
\hline Evaluasi dan pengawasan & Tinggi & 8 & 8,00 & Rendah \\
& Sedang & 24 & 24,00 & \\
& Rendah & 68 & 68,00 & \\
\hline Inisiatif sendiri & Tinggi & 3 & 3,00 & Rendah \\
& Sedang & 18 & 18,00 & \\
& Rendah & 79 & 79,00 & \\
\hline Pemahaman terhadap ekosistem & Tinggi & 31 & 31,00 & Rendah \\
mangrove & Sedang & 35 & 35,00 & \\
& Rendah & 34 & 34,00 & \\
\hline
\end{tabular}


Tabel 2. Indikator Pembangunan Berkelanjutan Sumberdaya Ekosistem Mangrove

\begin{tabular}{|c|c|c|c|c|c|}
\hline Dimensi & Indikator & Bobot & Keterangan & Nilai & Skor \\
\hline \multirow[t]{4}{*}{ Ekonomi } & Pendapatan masyarakat & 5 & $\begin{array}{l}\text { Pendapatan masyarakat Desa Blongko tergolong rendah apabila } \\
\text { dihubungkan dengan meningkatnya kebutuhan primer rumah } \\
\text { tangga saat ini. Pendapatan masyarakat sebelum dan sesudah } \\
\text { adanya DPL tidak menunjukkan kenaikan yang signifikan. }\end{array}$ & $\mathrm{B}$ & 10 \\
\hline & Produksi perikanan & 3 & $\begin{array}{l}\text { Hasil tangkapan ikan ataupun biota di ekosistem mangrove } \\
\text { mengalami penurunan dari tahun ke tahun. }\end{array}$ & C & 3 \\
\hline & $\begin{array}{l}\text { Investasi di sektor } \\
\text { perikanan }\end{array}$ & 2 & $\begin{array}{l}\text { Jumlah kapal penangkapan ikan jenis pukat cincin menurunan } \\
\text { akibat kenaikan BBM dan mahalnya biaya operasional. }\end{array}$ & C & 2 \\
\hline & & & & Jumlah & 15 \\
\hline \multirow[t]{6}{*}{ Ekologi } & Vegetasi mangrove & 3 & Masih adanya indikasi kerusakan ekosistem mangrove. & $\mathrm{C}$ & 3 \\
\hline & $\begin{array}{l}\text { Kerusakan lingkungan } \\
\text { pesisir }\end{array}$ & 3 & $\begin{array}{l}\text { Indikasi terjadinya abrasi dapat dilihat dari peningkatan jangkauan aksi } \\
\text { laut ke arah darat. Erosi pada sempadan sungai dan sedimentasi } \\
\text { masih terlihat di sepanjang sungai dan intrusi air laut mencapai ke } \\
\text { sumur-sumur masyarakat. }\end{array}$ & $\mathrm{C}$ & 3 \\
\hline & Kualitas perairan & 2 & $\begin{array}{l}\text { Perairan ekosistem mangrove masih baik dan mendukng kehidupan } \\
\text { biota yang berasosiasi didalamnya }\end{array}$ & $A$ & 6 \\
\hline & $\begin{array}{l}\text { Hasil tangkapan dan } \\
\text { kelimpahan spesies target. }\end{array}$ & 1 & $\begin{array}{l}\text { Penangkapan biota dan ikan pada sekitar ekosistem mangrove } \\
\text { mengalami penurunan baik kuantitas dan kualitas. Hal ini dapat dilihat } \\
\text { dari menurunnya jumlah tangkapan kepiting bakau dan kerang darah } \\
\text { serta burung maleo dan monyet hitam }\end{array}$ & C & 1 \\
\hline & Dampak pemanfaatan & 1 & $\begin{array}{l}\text { Penebangan dan pembuangan limbah rumah tangga ke ekosistem } \\
\text { mangrove masih terjadi.. }\end{array}$ & C & 1 \\
\hline & & & & Jumlah & 14 \\
\hline \multirow[t]{5}{*}{ Sosial } & $\begin{array}{l}\text { Pemahaman akan } \\
\text { ekosistem mangrove }\end{array}$ & 4 & $\begin{array}{l}\text { Masih tergolong rendah karena kurangnya sosialisasi, evaluasi, dan } \\
\text { monitoring. }\end{array}$ & C & 4 \\
\hline & Tingkat pendidikan formal & 3 & $\begin{array}{l}\text { Jumlah masyarakat yang tidak tamat SD serta banyaknya anak yang } \\
\text { putus sekolah masih cukup tinggi. }\end{array}$ & C & 3 \\
\hline & $\begin{array}{l}\text { Pemahaman akan } \\
\text { kesehatan dan lingkungan }\end{array}$ & 2 & $\begin{array}{l}\text { Minimnya sarana dan prasarana kesehatan serta keterbatasan tenaga } \\
\text { medis membuat masyarakat kurang mendapat pelayanan kesehatan. } \\
\text { Indikasi lainnya adalah anak-anak di desa ini masih banyak yang } \\
\text { kekurangan gizi. }\end{array}$ & C & 2 \\
\hline & $\begin{array}{l}\text { Peningkatan jumlah } \\
\text { penduduk }\end{array}$ & 1 & $\begin{array}{l}\text { Meningkatnya jumlah penduduk membuat tekanan terhadap } \\
\text { ekosistem semakin besar. }\end{array}$ & C & 1 \\
\hline & & & & Jumlah & 10 \\
\hline \multirow[t]{3}{*}{$\begin{array}{l}\text { Pengaturan } \\
\text { (Govemance) }\end{array}$} & Partisipasi masyarakat & 6 & $\begin{array}{l}\text { Minimnya pengetahuan dan pemahaman, serta dualisme masyarakat } \\
\text { tentang DPL membuat partisipasi masyarakat masih rendah. } \\
\text { Indikasi adanya penurunan ketaatan terhadap peraturan yang ada di }\end{array}$ & C & 6 \\
\hline & $\begin{array}{l}\text { Ketaatan terhadap } \\
\text { peraturan DPL }\end{array}$ & 4 & $\begin{array}{l}\text { DPL terjadi dalam beberapa tahun terakhir ini,dapat dilihat dari kegiatan } \\
\text { pemanfaatan yang bersifat destruktif di ekosistem mangrove. Hal ini } \\
\text { meningkat seining dengn kenaikan harga barang dan BBM. Selain itu } \\
\text { setelah proyek pesisir berakhir pihak pngelola DPL kurang } \\
\text { memperhatikan pelanggaran diDPL. }\end{array}$ & C & 4 \\
\hline & & & & Jumlah & 10 \\
\hline
\end{tabular}

Keterangan : $\mathrm{A}=$ Membaik, $\mathrm{B}=$ Konstan/tetap, $\mathrm{C}=$ Menurun/memburuk 


\section{Strategi pelestarian ekosistem mangrove Desa Blongko}

Dengan melihat indikator pembangunan berkelanjutan pada sumberdaya ekosistem mangrove maka tindak lanjutnya adalah membuat alternatif strategi pelestarian untuk meminimalkan kerusakan mangrove dan kendala yang telah dianalisis sebelumnya. Hasil analisis terhadap semua indikator tersebut dapat menggambarkan kondisi ekosistem mangrove dan pengelolaannya saat ini. Untuk dimensi yang semakin memburuk kondisinya maka tindakan-tindakan perbaikan harus segera dilakukan untuk mencegah meluasnya dampak, sebaliknya untuk dimensi yang konstan/membaik, maka program-program pemeliharaan dan pengembangan harus terus dikembangkan. Hal ini diharapkan dapat meminimalkan ancaman dan kendala dalam pelestarian ekosistem mangrove.

Strategi yang digunakan dalam mengatasi masalah ini yaitu : pengembangan sumberdaya manusia, perlindungan dan pelestarian sumberdaya alam, serta penegakan hukum dan kelembagaan di Desa Blongko. Ketiga strategi besar ini dijabarkan dalam beberapa alternatif strategi pelestarian. Dari skor yang diperoleh maka dimensi sosial dan pengaturan (governance) mendapatkan peringkat pertama dalam penentuan alternatif strategi pelestarian ekosistem mangrove, diikuti dengan dimensi ekonomi dan ekologi.

Alternatif strategi pelestarian ekosistem mangrove terdiri dari 4 strategi, yaitu strategi pelestarian pada dimensi sosial, strategi pelestarian pada dimensi pengaturan (governance), strategi pelestarian pada dimensi ekologi, dan strategi pelestarian pada dimensi ekonomi. Strategi pelestarian pada dimensi sosial terdiri dari 2 hal. Pertama, melalui strategi peningkatan pemahaman tentang ekosistem mangrove melalui pendidikan dan keagamaan serta peningkatan partisipasi masyarakat. Pengembangan teknologi berwawasan lingkungan di sektor pertanian dan perikanan untuk menghindari kerusakan ekosistem dan konflik pemanfaatan. Kedua, melalui strategi pengembangan potensi wisata bahari khususnya wisata rohaniah. Strategi pelestarian pada dimensi pengaturan (governance) terdiri dari 2 hal. Pertama, melalui revisi peraturan tentang DPL dengan didasari oleh undang-undang pendukung Pengelolaan wilayah pesisir dan pulau-pulau kecil. Kedua, melalui evaluasi dan pengawasan terhadap program dan kegiatan pengelolaan sumberdaya pesisir serta aturan yang telah ditetapkan untuk menjaga dan melestarikan ekosistem mangrove. Strategi pelestarian pada dimensi ekologi terdiri dari 2 hal. Pertama, melalui penataan ruang pesisir untuk menghindari konflik pemanfaatan ruang serta menekan laju kerusakan lingkungan akibat kegiatan manusia. Kedua, melalui rehabilitasi kawasan mangrove yang rusak dengan melibatkan masyarakat dalam pelaksanaannya. Strategi pelestarian pada dimensi ekonomi terdiri dari 2 hal. Pertama, melalui pengembangan usaha alternatif di sektor perkebunan dan perikanan. Kedua, melibatkan pihak swasta dan pemerintah dalam pengembangan usaha di bidang perkebunan, perikanan, dan wisata.

Hasil analisis strategi pelestarian ekosistem mangrove di atas menunjukkan bahwa konsep daerah perlindungan laut yang ada di Desa Blongko masih perlu dibenahi untuk mengoptimalkan partisipasi masyarakat dalam kegiatan-kegiatan pelestarian ekosistem mangrove. Hal ini terlihat dari kurangnya kesadaran masyarakat akan arti pentingnya menjaga dan melestarikan lingkungan dan sumberdaya yang ada. Partisipasi masyarakat sampai saat ini tergantung pada kegiatan-kegiatan yang diprakarsai oleh pemerintah ataupun LSM, sehingga 
kemandirian yang direncanakan pada awal pembuatan DPL belum tercapai.

\section{Pengembangan Sumberdaya Manusia}

Pendekatan melalui pembelajaran dengan memberikan bentuk pada sebuah program yang dirancang dan komitmen untuk melestarikan ekosistem mangrove dapat dilakukan dengan peningkatan partisipasi masyarakat. Sampai saat ini inisiatif untuk kegiatan-kegiatan pelestarian mangrove seperti penanaman kembali dan loka karya masih diprakarsai oleh pemerintah dan LSM. Selain itu juga kegiatan ini hanya menitik beratkan kepada penanaman mangrove.

Pengembangan potensi yang dimiliki oleh Desa Blongko dapat dilakukan dengan beberapa strategi. Panorama pantai dan keanekaragaman sumberdaya yang dimiliki desa ini dapat menjadi modal dalam pengembangan wisata bahari. Ketersedian lahan dan keinginan masyarakat untuk menigkatkan pendapatan dapat dijadikan pemicu untuk pengembangan disektor ini. Kegiatan wisata di Desa ini dapat berupa wisata religi dan wisata ilmiah. Alasan pemilihan kedua kegiatan wisata ini adalah dampak terhadap lingkungan dan sumberdaya yang ada. Tekanan yang diberikan akibat dari kedua kegiatan wisata tersebut masih dapat ditoleransi dan dikendalikan dibandingkan kegitan wisata lain. Perbaikan infrastruktur, ketersedian sarana dan prasarana untuk umum, ketersediaan air bersih, dan keamanan adalah beberapa hal yang perlu diperhatikan dalam pengembangan kawasan wisata ini. Pendampingan pemerintah daerah dan pihak swasta untuk menunjang kegiatan ini dirasakan sangat penting mengingat masih minimnya sumberdaya manusia yang ada di desa ini.

Peningkatan pendapatan bagi masyarakat yang bermata pencaharian nelayan merupakan salah satu strategi penting dalam pelestarian ekosistem mangrove. Pengembangan di sektor perikanan antara lain dilakukan dengan cara pengetahuan tentang teknik penangkapan ikan, pembelajaran tentang cara penangkapan ikan yang tidak merusak lingkungan, penambahan armada penangkapan, ketersediaan bahan bakar minyak dan teknik pemasaran. Sampai saat ini teknik penangkapan ikan masih bersifat tradisional dan sangat tergantung pada musim dan keadaan bulan. Keterbatasan teknologi mengakibatkan daerah penangkapan ikan tidak jauh dari tempat tinggal, hal ini untuk mengurangi pengeluaran yang besar terhadap bahan bakar. Beberapa cara penangkapan seperti penggunaan panah dan teknik penggunaan bubu yang salah masih sering dijumpai di desa ini padahal secara tidak langsung hal ini menjadi ancaman terhadap kelestarian ekosistem pesisir. Minimnya pengetahuan akan fungsi dari terumbu karang mengakibatkan masyarakat masih menggunakan caracara yang merusak untuk mendapatkan ikan atau biota lainnya yang hidup pada daerah pesisir.

Kegiatan di sektor perikanan yang ada di desa ini hanya pada perikanan tangkap saja. Kegiatan seperti pengolahan hasil perikanan dan budidaya belum terlihat ada di desa ini. Alternatif strategi untuk pengembangan sektor perikanan adalah pelatihan tentang pengembangan budidaya rumput laut dan pengembangan tambak udang. Pengembangan kedua alternatif kegiatan perikanan ini didasarkan pada posisi geografis desa yang kurang mendapat pengaruh dari aktifitas laut seperti arus dan gelombang. Selain itu pencemaran yang ada di desa ini masih belum berpengaruh besar terhadap lingkungan perairan yang ada. Lokasi budidaya rumput yang disarankan adalah daerah di depan zona inti. Keterlindungan dari arus dan kualitas perairan yang masih baik memungkinkan kegiatan budidaya ini dikembangkan di desa ini. Selain itu 
pengembangan tambak dengan pendekatan rekayasa terhadap ekosistem mangrove diharapkan dapat menjadi solusi alternatif dalam pengembangan sektor perikanan di desa ini. Mina hutan sebagai salah satu alternatif rekayasa ekologi memiliki peranan penting dalam pelestarian ekosistem mangrove di samping nilai manfaat yang harapkan juga tinggi. Beberapa pola tambak yang ada di Indonesia seperti pola empang parit dan pola komplangan dirasakan dapat diterapkan pada daerah ini. Tentu saja untuk menerapkan semua alternatif strategi ini diperlukan kajian yang lebih mendalam tentang semua dampak yang akan ditimbulkan dari kegiatan ini. Kemampuan daya dukung lingkungan terhadap perubahan yang nantinya akan diberikan pada daerah ini, menjadi salah satu pertimbangan dalam pengembangan strategi ini. Bantuan serta pendampingan dari pemerintah sangat dibutuhkan dalam kegiatan ini, selain itu pelibatan pihak swasta juga dapat memberikan kontribusi yang berarti dalam pengembangan di sektor perikanan yang ada di Desa Blongko.

Perkebunan yang menjadi sektor andalan desa ini, sektor ini memberikan tekanan yang cukup besar bagi lingkungan dan sumberdaya yang ada. Keterbatasan teknologi dan pengetahuan membuat kegiatan perkebunan desa ini belum maksimal. Diharapkan dengan penataan ruang di desa ini maka dapat meminimalkan tekanan terhadap ekosistem yang ada. Masalah sedimentasi dan erosi yang terjadi terus menerus diakibatkan pembukaan lahan yang tidak memperhatikan kontur tanah. Daerah perkebunan yang terletak pada daerah bukit membuat tingkat sedimentasi sangat tinggi pada muara sungai. Pengembangan usaha alternatif selain kopra dan cengkih dapat dilakukan dengan cara pengembangan pembuatan nata de coco. Alternatif usaha ini dapat dikembangkan mengingat potensi kelapa yang ada di desa ini sangat besar dibandingkan komoditi lain. Usaha ini tidak memerlukan modal yang besar dan pemasarannya mudah untuk dilakukan. Bahan dasar dari pembuatan nata de coco adalah air kelapa. Karena keterbatasan informasi dan teknologi sampai saat ini air kelapa belum digunakan dan hanya menjadi limbah dari pembuatan kopra. Selain itu pengembangan pembuatan Virgin Coconut Oil (VCO) didesa ini masih belum terlihat padahal produk ini menjadi konsumsi masyarakat dunia sebagai suplemen makanan. Harganya yang mahal membuat beberapa tempat di Indonesi telah memulai untuk mengembangkan produk ini. Bahan dasar dari pembuatan VCO ini adalah buah kelapa. Pengembangan beberapa alternatif usaha untuk pengembangan diesektor perkebunan ini tentunya dengan memperhatikan beberapa kriteria dalam pelaksanaannya. Kegitatan ini harus mampu meminimalkan dampak terhadap ekosistem dan sumberdaya alam yang ada serta mampu meningkatkan taraf hidup masyarakat yang ada di Desa Blongko.

Beberapa usaha alternatif pengembangan potensi yang ada di desa ini diharapkan dapat memberikan keuntungan bagi masyarakat Desa Blongko. Secara tidak langsung hal ini dapat mengurangi tekanan langsung terhadap ekosistem mangrove. Peningkatan kesejahteraan diikuti dengan pengurangan angka kemiskinan serta meningkatnya tingkat pendidikan menjadi tujuan jangka panjang dari alternatif usaha-usaha ini.

Penegakan Hukum dan Kelembagaan Pelibatan seluruh masyarakat diharapkan dapat mengurangi adanya kecemburuan sosial dikalangan masyarakat dan penerapan semua kebijakan yang disepakati tidak menimbulkan adanya perbedaan persepsi 
dan konflik di masyarakat. Dasar pertimbangan dari pembuatan peraturan desa didasari pada beberapa undangundang yang ada seperti undang-undang pengelolaan wilayah pesisir dan pulaupulau kecil (UU No.27 Tahun 2007), undang-undang tentang penataan ruang (UU No.26 Tahin 2007), undang-undang kehutanan, dan undang-undang lain yang dirasakan relevan untuk dijadikan dasar pertimbangan pembuatan peraturan desa. Peraturan ini mempunyai tujuan untuk mengurangi tekanan terhadap seluruh sumberdaya alam yang ada dipesisir Desa Blongko khususnya ekosistem mangrove. Merevisi peraturan desa yang mengatur tentang pemanfaatan sumberdaya ekosistem mangrove yang lestari dan bekelanjutan adalah suatu langkah bijak dalam hal penegakan hukum dan penguatan kelembagaan. Hal ini didukung oleh adanya kewenangan desa dalam membuat peraturan desa melalui rapat desa yang melibatkan seluruh masyarakat

\section{Perlindungan Dan Pelestarian Sumberdaya Alam}

Pelestarian ekosistem mangrove tidak terlepas dari partisipasi masyarakat untuk ikut dalam setiap kegiatan yang telah diprogramkan. Rehabilitasi kawasan mangrove yang adalah bagian dari tahap perencanaan dalam pengelolaan DPL menjadi bagian penting yang tidak terpisahkan dari pengelolaan sumberdaya alam desa ini. Pelaksanaan rehabilitasi mangove harus melibatkan seluruh masyarakat yang ada di Desa Blongko. Pentingnya pengetahuan tentang cara penanaman mangrove yang baik untuk menghindari kegagalan dalam penanaman dilakukan dengan cara pembelajaran bersama seluruh masyarakat tentang cara penanaman, pemilihan bibit, penentuan lokasi sampai pada pemeliharaan mangrove.

Evaluasi dan pengawasan terhadap semua program serta rencana kegiatan pengelolaan sumberdaya pesisir adalah bagian penting yang harus dilakukan. Hal ini untuk menilai seberapa jauh keberhasilan suatu program yang dijalankan untuk mengurangi kerusakan ekosistem pada umumnya dan mangrove khususnya. Selah satu kelemahan pada DPL Blongko adalah kurangnya evaluasi terhadap semua program yang telah dibuat selama ini. Kedepannya diharapkan semua program yang akan dijalankan akan dievaluasi secara berkala. Evaluasi ini akan memberikan gambaran tentang sejauh mana program ini memberikan dampak terhadap masyarakat sebagai pelaksana program dan ekosistem mangrove sebagai objek yang dilestarikan.

\section{KESIMPULAN}

Berdasarkan hasil penelitian serta pembahasan yang telah dibuat, maka dapat diambil kesimpulan sebagai berikut :

1. Kerusakan ekosistem mangrove diakibatkan oleh pemanfaatan yang bersifat destruktif terhadap sumberdaya yang ada. Hal ini berdampak pada abrasi, sedimentasi, dan intrusi air laut serta menurunnya jumlah fauna pada ekosistem mangrove.

2. Kondisi fisik dan kimia perairan pada ekosistem mangrove di Desa Blongko masih dalam keadaan yang baik, sehingga pemulihannya masih dapat dilakukan dengan cara mengurangi tekanan terhadap ekosistem.

3. Masih kurangnya pemahaman masyarakat terhadap ekosistem mangrove dan beberapa karakteristik masyarakat seperti rendahnya pendapatan dan pendidikan serta tingkat partisipasi, membuat pemanfaatan yang bersifat merusak terhadap ekosistem mangrove tidak dapat dihindari.

4. Penegakan hukum dan penguatan kelembagaan adalah salah satu upaya untuk mengelola sumberdaya di pesisir Desa Blongko. Merevisi 
peraturan yang telah di buat untuk DPL diharapkan dapat melindungi sumberdaya yang ada, tanpa mengesampingkan upaya pengembangan terhadap sumberdaya manusia dan potensi yang ada di Desa Blongko.

\section{DAFTAR PUSTAKA}

Aksornkoae S. 1993. Ecology and Management of Mangrove. The IUCN Wetlands Programme. Bangkok. Thailand

Alongi DM, Trott LA, Wattayakorn G, Clough F. 2002. Below-Ground Nitrogen Cycling In Relation to Net Canopy Production in Mangrove Forests Of Southern Thailand. Marine Biology 140: 855-864

Barkey R. 1990. Mangrove Sulawesi Selatan (Struktur, Fungsi, Dan Laju Degradasi). Prosiding Seminar Keterpaduan Antara Konservasi dan tata Guna Lahan Basah di Sulawesi Selatan. LIPI-Pemda Sulawesi Selatan.

Bengen DG. 2002a. Pengenalan dan Pengelolaan Ekosistem Mangrove. Pusat Kajian Sumberdaya Pesisir dan Lautan - IPB. Bogor.

Bengen DG. 2002b. Sinopsis, Ekosistem dan Sumberdaya Alam Pesisir dan Laut Serta Prinsip Pengelolaannya. Pusat Kajian Sumberdaya Pesisir dan Lautan - IPB. Bogor

Bird ECF. 1970. Coast And Introduction To Systimatic Geomorphology. Vol IV. Massachusettes Institute of Technology. Cambridge. Massachusettes. Pp. 246.

Dahuri R, Rais J, Ginting SP, Sitepu MJ, 2004. Pengelolaan Sumberdaya Wilayah Pesisir dan Lautan Secara Terpadu. PT Pradnya Paramitha. Jakarta.

Dahuri R, 2003. Keanekaragaman Hayati Laut: Aset Pembangunan
Berkelanjutan Indonesia. PT Gramedia Pustaka Utama. Jakarta. English S, Wilkinson C, Baker V (editors). 1994. Survey Manual For Tropical Marine Resources. Australian Institute of Marine Science. Townsville.

[FAO] Food Agriculture Organization. 1994. Mangrove Forest Management Guidelines. FAO Forestry Paper 117, Rome.

Gunarto. 2004. Konservasi Mangrove Sebagai Pendukung Sumber Hayati Perikanan Pantai. Jurnal Litbang Pertanian 23:1-6.Sulawesi Selatan.

Gopal B, Chauchan M. 2006. Biodiversity and its conservation in the Sundarban Mangrove Ecosystem. Aquatic Sciences 68:338-354.

Grasso M .1998. Ecological-Economic Model for Optimal Mangrove Trade Off Between Forestry and Fishery Production: Comparing a Dynamic Optimization and a Simulation Model. Ecological Modelling 112: 131-150.

Holmer M, Olsen AB. 2002. Role of decomposition of mangrove and seagrass detritus in sediment carbon and nitrogen cycling in a tropical mangrove forest. Mar. Ecol. Prog. Ser. 230: 87-101

In Young Wang. 1981. Managemant of Rural Change in Korea. University Press, Seoul. 56-64

Kasmidi M, Ratu A, Armada E, Mintahari J, Maliasar I, Yanis D, Lumolos F, dan Mangampe N. 1999a. Profil Sumberdaya Wilayah Pesisir Desa Blongko, Kecamatan Tenga,Kabupaten Minahasa, Sulawesi Utara. Proyek Pesisir. University of Rhode Island, Coastal Resources Center, Naragansettt, Rhode Island, USA, $32 \mathrm{pp}$.

Kasmidi M, Ratu A, Armada E, Mintahari J, Maliasar I, Yanis D, Lumolos F, dan 
Mangampe N, Kapena $P$, dan Mongkol M. 1999b. Rencana Pengelolaan Daerah Perlindungan Laut dan Pembangunan Sumberdaya Wilayah Pesisir Desa Blongko Kecamatan Tenga, Kabupaten Minahasa, Sulawesi Utara. University of Rhode Island, Coastal Resources Center, Rhode Island, USA dan Bappeda Kabupaten Minahasa, Sulawesi Utara , Indonesia, 59 pp.

Kasmidi M. 2000. Proses Daerah Perlindungan Laut Berbasis Masyarakat: Pengalaman pengelolaan Sumberdaya Pesisir di Sulawesi Utara, Contoh Kasus Daerah Perlindungan Laut Blongko. Pp. 50-57. Prosiding Konperensi Nasional II Pengelolaan Sumberdaya Pesisir dan Lautan Indonesia. Makasar 15 - 17 Mei 2000.Kenneth FD. 1979. Forest Management Regulation and Valuation. Mc. Graw Hill Book Co. Ltd. New York.

Kenneth FD. 1979. Forest Management Regulation and Valuation. Mc. Graw Hill Book Co.Ltd. New York.

Khazali M. 2001. Potensi, Peran, dan Pengelolaan Mangrove. Seminar dan Lokakarya Nasional Pengelolaan dan Pemanfaatan Pulau Nusa kambangan Sebagai Sisa-sisa Hutan Hujan Dataran Rendah Berupa Ekosistem Kepulauan di Era Otonomi Daerah. Yogyakarta. 28-29 Mei 2001.

Kitamura S, Anwar A, Chaniago A, Baba S. 1997. Handbook of mangroves in Indonesia, Bali. JICA dan ISME.

Kramadibrata I. 1975. Ekologi Hewan. Biologi. Fakultas MIPA. Institut Teknologi Bandung. Bandung.

Krebs JC.1989. Ecological Methodology. Harper and Row Publisher. New York.
Kusen JD, Rotinsulu C, Siahaenia A, Sukmara A. 1999. Laporan Data Dasar Sumberdaya Wilayah Pesisir Dea Blongko, Kabupaten Minahasa. Provinsi Sulawesi Utara. Proyek Pesisir. Technical Report TE-99/24-1. University of Rhode Island, Coastal Resources Center, Narragansett, Rhode Island, USA. pp.49.

Kusumastanto T. 2002. Reposisi Ocean Policy Dalam Pembangunan Ekonomi Indonesia di Era Otonomi Daerah. Disampaikan Dalam Orasi IImiah Pengukuhan Guru Besar Tetap Bidang IImu Kebijakan Ekonomi Perikanan dan Kelautan FPIK IPB. Bogor.

Manembu I. 2004. Partisipasi Masyarakat Dalam Pengelolaan Derah Perlindungan Laut di Pulau Gangga, Bangka dan Talise. [tesis]. Bogor : Program Pascasarjana, Institut Pertanian Bogor.

Nagelkerken I, Van Der Velde G. 2004. Are Caribbean Mangroves Important Feeding Grounds For Juvenile Reef Fish From Adjacent Seagrass Beds. Mar. Ecol. Prog. Ser. 274: 143-151.

Nazili M. 2004. Strategi Pengelolaan Ekosistem Mangrove Berbasis Partisipasi Masyarakat di Kawasan Teluk Pangpang-Banyuwangi. [tesis]. Bogor : Program Pascasarjana, Institut Pertanian Bogor.

Noor YR, Khazali M, Suryadiputra INN. 1999. Panduan Pengenalan Mangrove Indonesia. PKA/WI-IP. Bogor.

Odum E. 1971. Fundamentals of ecology. 3rd ed. W.B. Saunders. Philadelphia.

Pelle W. 2002. Studi Geomorfologi Pantai Daerah Perlindungan Laut di Desa Blongko [skripsi]. Manado : Fakultas Perikanan dan IImu 
Kelautan. Universitas Sam Ratulangi.

Pogalin NL. 1998. Kondisi Sosial Ekonomi Dan Lingkungan Hidup Masyarakat Di Desa Blongko Kecamatan Tenga Kabupaten Minahasa. [skripsi] Manado: Fakultas Perikanan dan IImu Kelautan. Universitas Sam Ratulangi.

[PPGK] Pusat Pengembangan Geologi Kelautan. 1996. Survei Tematik Kelautan Terintegrasi. Inventarisasi Sumberdaya Geologi dan Geofisika Kelautan di Kawasan MCMA Manado dan Sekitarnya. Bandung. 112 hal.

Resosoedarmo RS, Kartawinata K, Soegiarto A. 1980. Pengantar Ekologi. C.V. Remadja Karya. Cetakan I. Bandung.

Soeriatmadja, R.E., 1981. IImu Lingkungan. Biologi. Fakultas MIPA. Institut Teknologi Bandung. Bandung

Schaduw J. 2005. Profil Desa Kelurahan Manado Tua Dua, Kecamatan Bunaken, Kota Manado, Provinsi Sulawesi Utara. [laporan praktek kerja lapang]. Manado : Fakultas Perikanan dan IImu Kelautan. Universitas Sam Ratulangi.

Skilleter G A dan Warren S. 1999. Effects Of Habitat Modification In Mangroves On The Structure Of Mollusc And Crab Assemblages. Elsevier. 244 : 107-129
Spitzer P M, Mattila J, Heck Jr K L. 1999. The effects of vegetation density on the relative growth rates of juvenile pinfish, Lagodon rhomboides (linneaus), in big Lagoon, florida. Elsevier. 244 :67-86

Sukardjo S. 2002. Integrated Coastal Zone Management (ICZM) in Indonesia : A View from a Mangrove Ecologist. Southeast Asian Studies. 40:200218.

Sutikno. 1993. Karakteristik Bentuk dan Geologi Pantai di Indonesia. Diklat PU wilayah 3 Dirjen Pengairan Dep.PU. Yogyakarta. 58 halaman

Sunarto. 1991. Geomorfologi Pantai. Pusat antar Universitas. Universitas Gadjah Mada. Yogyakarta. 50 halaman

Tokuyama A, Arakaki T.1988. Physical and Chemical Study of The Causes of Mangrove Death Along The Nakama River. Iriomote Island. Okinawa. Galaxea. 7:271-286.

Wantasen A. 2002. Kajian Ekonomi Ekologi Ekosistem Mangrove Daerah Perlindungan Laut Desa Talise, Kabupaten Minahasa, Sulawesi Utara [tesis]. Bogor : Program Pascasarjana, Institut Pertanian Bogor.

Wyrtki K. 1961. Physical Oceanology of the Southeast Asian Water. Vol.2. Univ. of California, San Diego, pp.195. 